\title{
What Is Our Point of View on "Energy Independence and Research for Economic and Environmental Sustainability"?
}

\author{
Romano Borchiellini", Francesco Demetrio Minuto \\ Energy Center Lab, Politecnico di Torino. Corso Duca degli Abruzzi 24, Torino 10129, Italy
}

Corresponding Author Email: romano.borchiellini@polito.it

https://doi.org/10.18280/ti-ijes.640110

Received: 9 April 2019

Accepted: 10 June 2019

\section{Keywords:}

development, energy independence, energy

research, sustainability

\begin{abstract}
The scope of this contribution is to stimulate critical debate on what are the implication of "energy independence" and "energy research" on the sustainable development of society. We point out how energy independence is strongly related to the penetration of renewable energy sources; and how the country's energy independence is not expected to be achieved in a short-medium period. Moreover, the trends of low found to the research on energy topics are not consistent with the pursuit of sustainable development of society.

With these observations, we want to contribute to the debate on what policies that will have an impact on the sustainable development of society, suggesting to focus on the point of view of those actors that will play the main role in the next future.
\end{abstract}

\section{INTRODUCTION}

Economic and environmental sustainability are crucial for the healthy development of society [1]. Many factors can contribute to achieving these goals, energy independence and a better understanding of the techno-economic dynamics thorough research are part of this roadmap [2].

Energy independence is a powerful concept that might look simple to grasp, which relates to the capability of self-provide energy for itself. Nevertheless, it can assume different interpretations depending on the subject of the matter; as energy independence on a building, a district, a village, or a country scale have different implications and issues. How we generate energy, how to provide energy security, what are the investments required, what is a policy framework coherent with the goals, how to shape the market addressing equality and energy poverty. All these questions can have different answers depending on what scale we are choosing to investigate.

\section{OBSERVATIONS}

The first consideration that is important to have in mind when we talk of energy independence and sustainability is the snapshot of the state of the energy generation [3]. The mandatory requirement for energy independence is the presence of distributed renewable energy sources since the traditional ones are geographically not equally distributed. In this sense, electricity represents one of the best energy vectors for its high ease of handle, distribute, use, and generate from renewable energy sources $[4,5]$. It also carries a strong perception of cleanness for the final user. Nevertheless, up to now, the primary energy used to generate electricity in the world is burning coal (see Figure 1-top). Unfortunately, this process is too cost-efficient and technologically easy to develop [6].
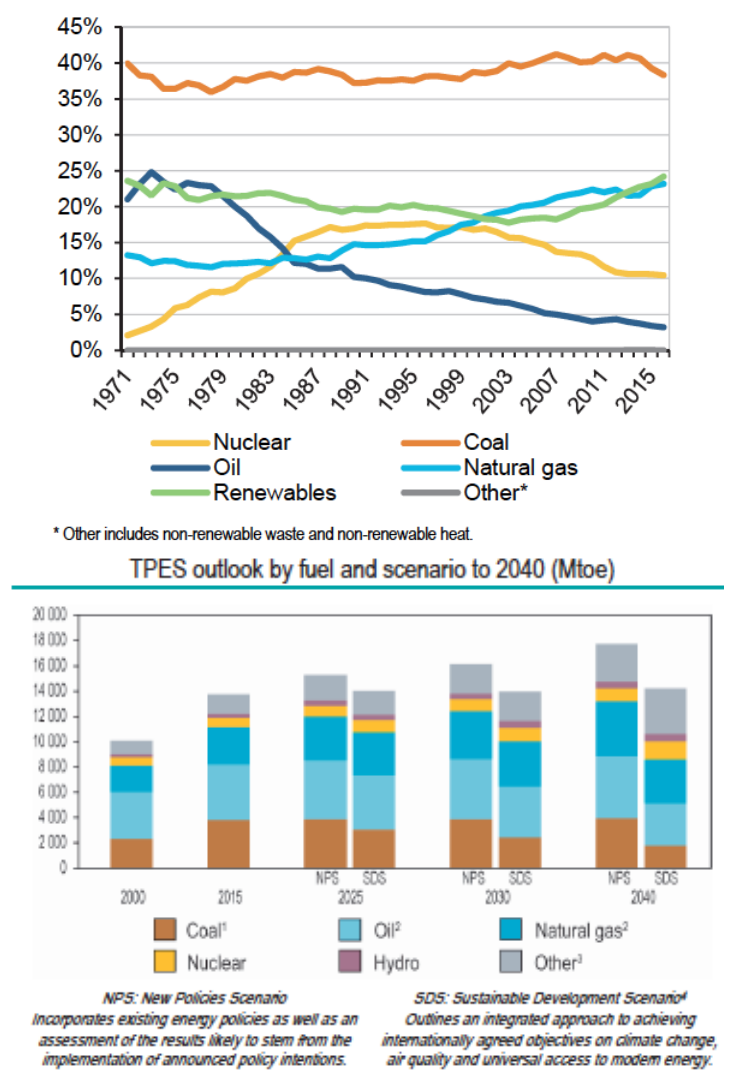

Figure 1. (top) World electricity generation mix 1971-2016 (Source: [3] IEA (2018) World Energy balances. All rights reserved.); (bottom) TPES outlook by fuel and scenario to 2040 (Source: [7] IEA (2018) Key world energy statistic. All rights reserved.)

In fact, both IEA "New Policies" (NPS) and "Sustainable Development" (SDS) scenarios at 2040 (see Figure 1-bottom) show a share of coal in the world energy mix almost equal to 
the one in 2015 for the NPS, and comparable to the one in 2000 for the SDS. On the other side, 2018 was the first year with a slow down of new installed RES capacity with an installation rate lower than the previous year (see Figure 2).

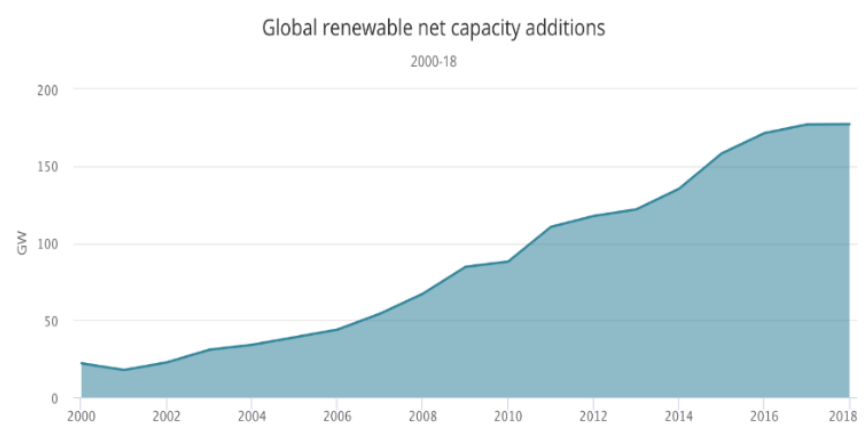

Figure 2. Global renewable net capacity additions 2000-2018 (Source: [4] IEA (2018), Renewables 2018. All rights reserved.)

Therefore, even hoping in a new boost of the rate of RES installations, considering the IEA estimation on the penetration of the electricity in the final uses of energy at 2030 [2], the electricity will not be the primary energy vector, as expected in the IEA "Future is Electric" scenario in Figure 3. The high penetration in buildings will be counterbalanced by very modest results in the Industry and Transport sectors, where the electricity will have a share of $21 \%$ and $38 \%$, respectively. Therefore, up to 2030, electric vehicles technology will not be part of the solution.

With this consideration in mind, it is clear that the technological solutions on the table up today are not enough to achieve the objective of energy independence.
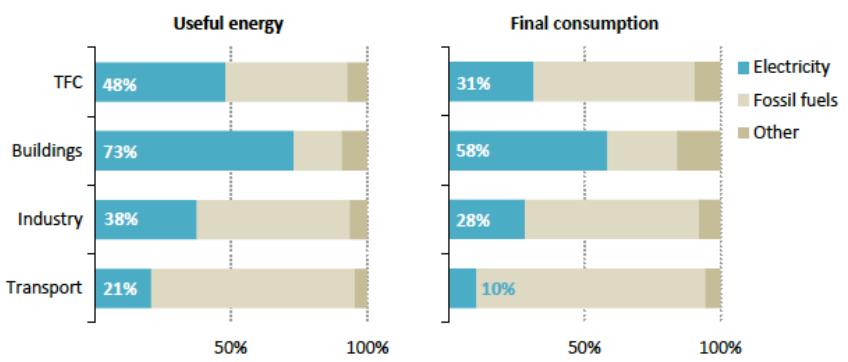

Figure 3. Electricity as a share of useful energy delivered an of total final consumption on 2030 in the "Future is Electric" IEA Scenario (Source: [2] IEA (2018) Energy Outlook 2018. All rights reserved.)

Therefore, the importance of research in developing new policy strategies, solutions for energy efficiency, new materials and technologies.

Figure 4 (top) shows that energy efficiency had the main impact on the reduction of the world energy consumption from 2000 to 2016, on the other side, it was just enough to balance the increase in energy consumption due to the economic growth. The TFC/GDP index in Figure 4 (bottom), assesses the improvement of the overall efficiency of the energy system in OECD countries. In fact, in spite of a modest increase in the total final consumption, they were capable of producing a higher economic value at parity of used energy.

Research on energy topics is, now more than before, crucial due to the high stake of the challenge. Everyone expects that the magic formula to solve the rebus to achieve a sustainable energy transition would pop up from some research institute at any moment.

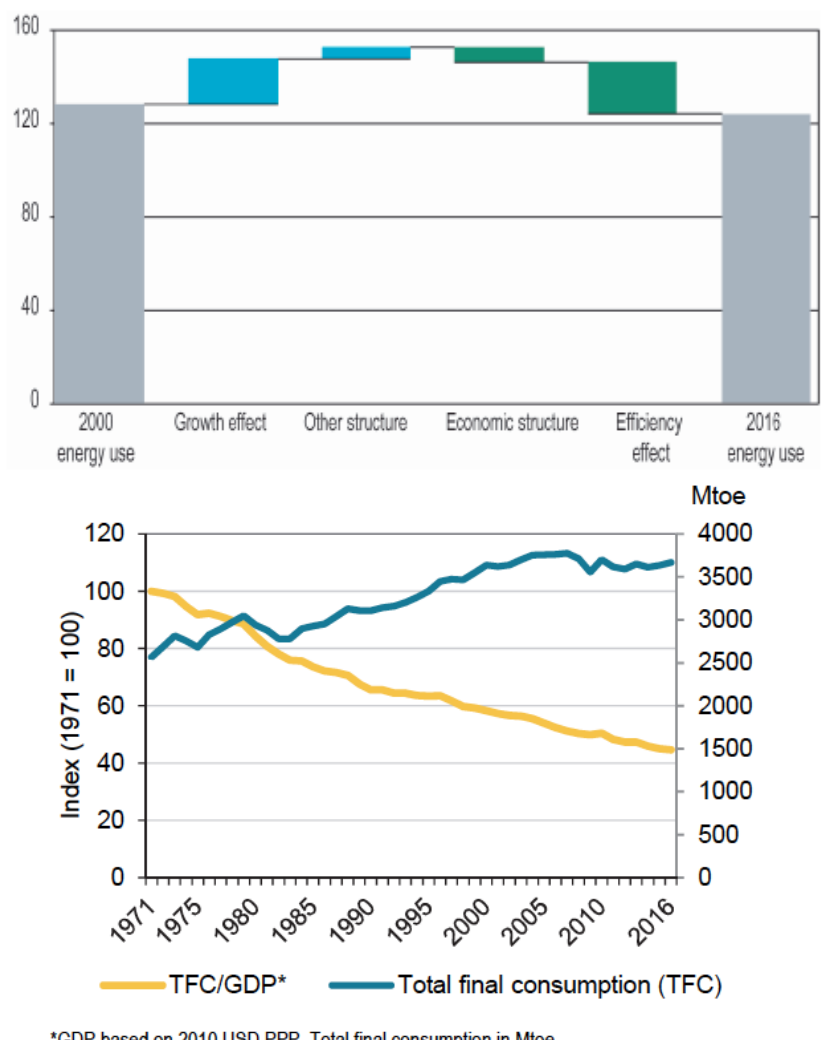

Figure 4. (top) Drivers of final energy consumption from 2000 to 2016 [EJ] (Source: [7] IEA (2018) Key world energy statistic. All rights reserved.); (bottom) Final energy intensity in OECD 1971-2016 (Source: IEA (2018) World Energy balances. All rights reserved.)

Nevertheless, analyzing the budged on energy research allocated worldwide in Figure 5, the inadequate investment in this field, even from those countries that have the highest energy demand, might be the result of a feeble trust in research.

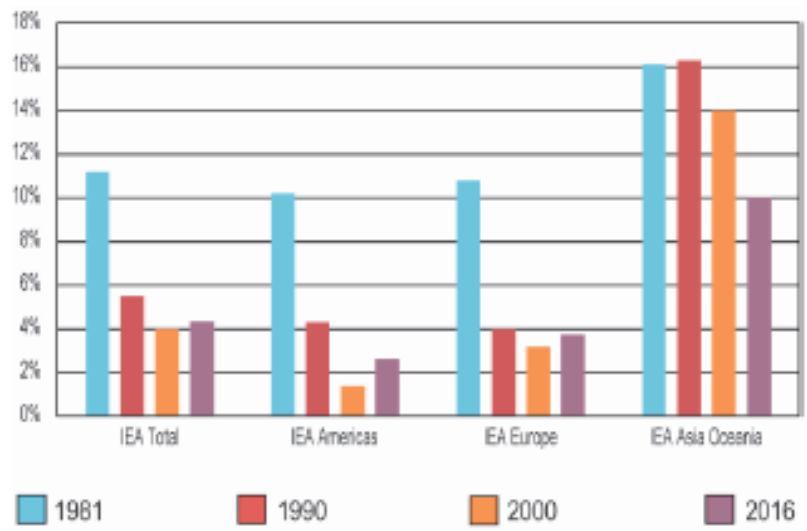

Figure 5. Share of energy in the expenditure in R\&D by region (Source [7] IEA (2018) Key world energy statistics. All rights reserved.)

One of the main critiques in pursuing energy independence as a model to achieve environmental sustainability in a globalized and interconnected world is that the effect of singular excellence is negligible on the whole global system. 
Moreover, in case we are still convinced that the world is steered by the economic and energetic choices of the European Union and the United States, Figure 6 shows how their GDP and energy use trends have gradually moved away from the world mean values, since the $70 \mathrm{~s}-80 \mathrm{~s}$. The future choices of China, India, and Africa on these matters [8] will have much more impact on the world and although the appreciation of the great effort of the European Union in the decarbonization of its energy system, the impact on these policies on the environment at a global scale will be not so decisive.

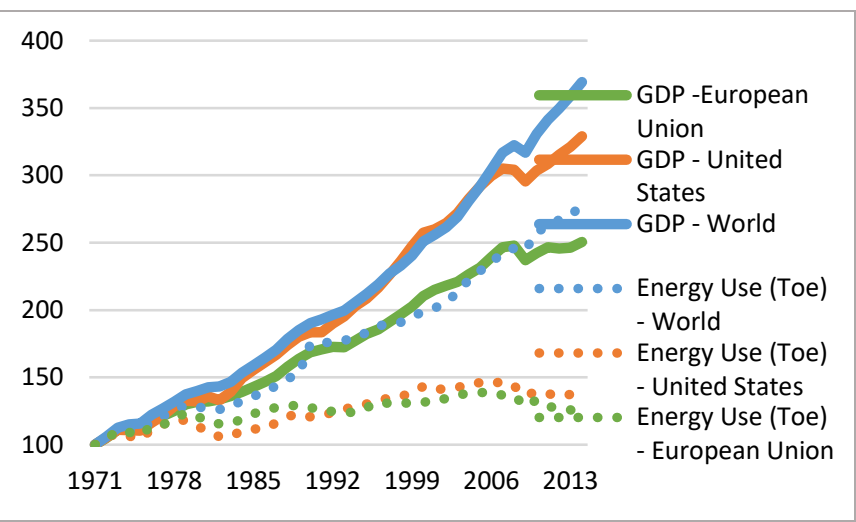

Figure 6. GDP and energy use 1971-2013 for World, United States and European Union (Data Source: World Bank World Development Indicators Data)

\section{CONCLUSIONS}

In this contribution, we focus our attention on the implications related to energy independence and energy research might have on the roadmap toward a more sustainable development of society.

We pointed out how the electricity generated from renewable energy sources is the key to achieve energy independence in countries where traditional energy sources are not geographically present. Nevertheless, considering the actual trends of RES penetration and scenario analysis, this goal is not expected to be met in a short-medium period.

Besides, we looked at "energy research" as the source of a breakthrough in developing new policy strategies, solutions for energy efficiency, new materials, and technologies. On one side, we hope that research can give the key to pursuing this goal, but on the other side, it is not adequately funded.

At last, we highlighted how, despite the great effort of European policymaker in engaging the decarbonization of the European energy system, the impact of these policies on the whole world environment would be very limited.
These considerations want to serve as a contribution to the discussion on the topics of sustainability in energy generation ad final use of it but suggesting to focus on the point of view of those actors that will play the main role in the next future.

\section{REFERENCES}

[1] Marchand, R., Genovese, A., Koh, S.C.L., Brennan, A. (2019). Examining the relationship between energy poverty and measures of deprivation. Energy Policy, 130 206-217. https://doi.org/10.1016/j.enpol.2019.03.026

[2] IEA (International Energy Agency). (2018). Energy Outlook 2018. Paris.

[3] IEA (International Energy Agency). (2018). World Energy Balances. Paris.

[4] IEA (International Energy Agency). (2018). Renewables 2018. Paris.

[5] Sen, S., Ganguly, S. (2017). Opportunities, barriers and issue with renewable energy development - A discussion. Renew. Sustain. Energy Rev., 69: 1170-1181. https://doi.org/10.1016/j.rser.2016.09.137

[6] Henderson, K.E. (2019). Contradictory governance norms within world society: Energy development strategies, environmental protection, and carbon dioxide emissions. Environ. Sociol., 5(4): 393-404. https://doi.org/10.1080/23251042.2019.1613031

[7] IEA (International Energy Agency). (2018). Key world energy statistics. Paris. https://www.iea.org/reports/keyworld-energy-statistics-2019.

[8] Peng, S., Yang, Y., Li, T., Smith, T.M., Tan, G.Z., Zhang, H.C. (2019). Environmental Benefits of Engine Remanufacture in China's Circular Economy Development. Environ. Sci. Technol., 53(19): 1129411301. https://doi.org/10.1021/acs.est.9b02973

\section{NOMENCLATURE}

$\begin{array}{ll}\text { GDP } & \text { Gross domestic product } \\ \text { IEA } & \text { International Energy Agency } \\ \text { NPS } & \text { New Policies scenario } \\ \text { OECD } & \begin{array}{l}\text { Organisation for economic co-operation and } \\ \text { development }\end{array} \\ \text { R\&D } & \text { Research and development } \\ \text { RES } & \text { Renewable energy sourcese } \\ \text { SDS } & \text { Sustainable Development scenario } \\ \text { TFC } & \text { Total final consumption } \\ \text { TOE } & \text { Tonne of oil equivalent } \\ \text { TPES } & \text { Total primary energy supply }\end{array}$

